\title{
ORAL HAEMOPHILI
}

\author{
W. Sims \\ Pathology Department, Royal Dental Hospital, London, W.C.2
}

\section{Plate LVII}

IT has been known for many years that haemophili can be isolated from the mouth. Pritchett and Stillman (1919), for example, recovered these organisms from 55 of 231 saliva specimens, and Fleming and Maclean (1930), in one of the earliest studies in which an antibiotic was utilised for selective isolation, concluded that haemophili were part of the normal flora.

Despite this, recent monographs and textbooks that contain detailed accounts of the bacteriology of the mouth either fail to mention haemophili at all (Bisset and Davis, 1960; Nolte, 1968) or state that they are occasionally present in small numbers (Burnett and Scherp, 1968). In this laboratory, haemophili are isolated by routine methods from approximately one-third of all oral clinical specimens submitted for investigation. No special methods are employed to recover haemophili, and indeed most strains are detected simply because their colonies resemble those of beta-haemolytic streptococci. Of 424 consecutively isolated strains 385 (90.8 per cent.) were identified as Haemophilus parahaemolyticus and 39 ( $9 \cdot 1$ per cent.) were non-capsulated $H$. influenzae.

The significance of isolating haemophili from oral infections cannot be established without a better knowledge of the occurrence of these organisms in the normal mouth, and it was the aim of the present work to provide this information.

\section{MATERIALS AND METHODS}

Bacteria. The following strains, which were used variously as controls and for comparison, were obtained through the courtesy of Dr S. P. Lapage of the National Collection of Type Cultures: Haemophilus influenzae (no. NCTC4560, Pittman's types $a-f$ no. NCTC 8465 , $7279,8469,8470,8472$ and 7918), H. parainfluenzae (no. NCTC4101), H. canis (no. NCTC 1659) and $H$. aphrophilus (no. NCTC5886). Dr Margaret Pittman of the National Institutes of Health, Bethesda, kindly supplied strains no. $180 \mathrm{a}, 181 \mathrm{a}$ and $128 \mathrm{a}$ of $H$. aegyptius.

Test for antibiotic sensitivity. The growth of haemophili, particularly the oral strains, was found to be much more vigorous on chocolate agar (heated 5 per cent. defibrinated horse blood agar) incubated in air +5 per cent. $\mathrm{CO}_{2}$ than in any broth media. The amounts of the antibiotics to be added to the selective chocolate agar were therefore determined by incorporating graded concentrations of the antibiotics in chocolate agar plates and inoculating them with the test strains of haemophili and dilutions of saliva.

The antibiotic sensitivities mentioned in the text were determined by our routine method which is that described by Stokes (1968, pp. 176-181) using Staphylococcus aureus (no. NCTC6571) as the control organism. The terms sensitive, moderately resistant and resistant, have the meaning ascribed to them by Stokes (p. 181). The antibiotic disks were obtained from Mast Laboratories Ltd, Liverpool.

Counts of haemophili in saliva specimens. Saliva, stimulated by chewing a wax pellet, was collected in sterile plastic vials from students and staff of the Royal Dental Hospital.

Received 26 Jan. 1970; accepted 23 Mar. 1970.

J. MED. MICROBIOL.-VOL. 3 (1970) 
Each specimen was thoroughly shaken, then $0.5 \mathrm{ml}$ was serially diluted in sterile 1.0 per cent. peptone water. With a sterile bent glass rod $0.1 \mathrm{ml}$ of the 1 in 5000,1 in 10,000 and 1 in 20,000 dilutions were spread over the surface of plates of chocolate agar containing 10 units of bacitracin and $5 \mu \mathrm{g}$ of cloxacillin per $\mathrm{ml}$. The plates were placed in anaerobic jars, which were evacuated and filled from a cylinder containing air +5 per cent. $\mathrm{CO}_{2}$. After incubation for $48 \mathrm{hr}$ at $37^{\circ} \mathrm{C}$ the plate of the dilution that yielded the largest number of colonies that were sufficiently discrete to allow accurate counting was selected and counted. Saliva specimens were collected in small batches and were diluted, plated and incubated within $1 \mathrm{hr}$ of collection.

Surface-area counts of haemophili. The technique of Johanson, Pierce and Sanford (1969) was used. The end of a $10-\mathrm{ml}$ Gillette "Scimitar" sterile, plastic syringe was aseptically removed and smoothed with a small sterile saw and file. The syringe was filled with sterile 20 per cent. gelatin and stored in a sterile container in the refrigerator until required. The surface area of the gelatin was $1.98 \mathrm{~cm}^{2}$. The area of mucosa to be sampled was dried with an air syringe and the gelatin firmly applied. One millilitre of the gelatin was extruded and sliced off with a sterile scalpel into $9 \mathrm{ml}$ of sterile 1.0 per cent. peptone water held in the waterbath at $37^{\circ} \mathrm{C}$. When the gelatin had melted it was thoroughly mixed, a further 1 in 10 dilution in peptone water was prepared, and $0.1 \mathrm{ml}$ of both dilutions was plated, incubated and counted as previously described.

Determination of growth-factor requirements. Each colony on the selected plates from the saliva counts was subcultured once on cloxacillin-bacitracin chocolate agar and then tested for growth on digest agar (Southern Group Laboratories, Lewisham, London), and digest agars containing $10 \mu \mathrm{g}$ per $\mathrm{ml}$ of both nicotinamide adenine dinucleotide (NAD) (Koch-Light Laboratories Ltd, Colnbrook, Bucks.) and haematin $\mathrm{HCl}$ (BDH Chemicals Ltd, Poole, Dorset), and NAD and haematin alone. The solutions of NAD and haematin $\mathrm{HCl}$ were prepared as described by Holt (1962) except that the NAD solution was passed through a $0.22 \mu \mathrm{m}$ pore size Millipore filter. Strains were subcultured by making small streaks $c .1 \mathrm{~cm}$ long and $1 \mathrm{~cm}$ apart with a very lightly inoculated loop; in this way, 24 cultures were accommodated on a single plate. Plates were incubated in air +5 per cent. $\mathrm{CO}_{2}$ for $48 \mathrm{hr}$ at $37^{\circ} \mathrm{C}$. H. influenzae (no. 4560), H. parainfluenzae and $H$. canis were used, as appropriate, as positive controls on all plates containing growth-factors; $H$. influenzae was used as a negative control on the plates containing only $\mathrm{V}$ or $\mathrm{X}$ factor, and $H$. parainfluenzae and $H$. canis were both inoculated on the plain digest agar plates as negative controls.

Production of capsules. Strains were incubated for $18 \mathrm{hr}$ in air +5 per cent. $\mathrm{CO}_{2}$ on a medium consisting of Brain Heart Infusion Agar (Difco) containing 2 per cent. Proteose Peptone no. 3 (Difco) and $10 \mu \mathrm{g}$ per $\mathrm{ml} \mathrm{NAD}$. For strains requiring $\mathrm{X}$ factor $10 \mu \mathrm{g}$ per $\mathrm{ml}$ of haematin $\mathrm{HCl}$ was added also. Strains showing iridescence were tested for agglutination in $H$. influenzae antisera types $a-f$ (Burroughs Wellcome and Co., London), and stained for capsules by the methods of Howie and Kirkpatrick (1934) and Duguid (1951).

Physiological tests. The capsule production test plates were used for testing for catalase and oxidase. The method of Stokes (p. 331) was used for testing for oxidase. Catalase was tested for by placing a small drop of 3 per cent. $\mathrm{H}_{2} \mathrm{O}_{2}$ on the bacterial growth and observing for effervescence with a hand lens. The methods described by Cowan and Steel (1965) were used for testing for reduction of nitrate and nitrite (p. 161), and indole production (p. 158) in digest broth was demonstrated with Kovacs' reagent; NAD and haematin $\mathrm{HCl}$ at a concentration of $10 \mu \mathrm{g}$ per $\mathrm{ml}$ were added to the basal media. Acid production from carbohydrates was tested in peptone water sugars (Southern Group Laboratories) to which a drop of NAD solution was added to give a concentration of $c .10 \mu \mathrm{g} \mathrm{per} \mathrm{ml.}$

Bile solubility was tested by the method of Pittman (1931), except that the organisms were grown in digest broth. Bile tolerance was tested by examining for growth on MacConkey agar and in digest broth containing 0.2 per cent. Teepol (Shell Ltd) (Jameson and Emberley, 1956). $10 \mu \mathrm{g} \mathrm{NAD}$ was added to each $\mathrm{ml}$ of these media.

Haemolysis was tested for on 5 per cent. defibrinated horse blood agar layered plates incubated in air at $37^{\circ} \mathrm{C}$ for $48 \mathrm{hr}$.

Haemagglutination of human group-O red cells was tested for by mixing $0.4 \mathrm{ml}$ of the 
Oral haEMOPHILI



FIGURE.-An 18-hr culture of an oral, capsulated V-dependent strain of haemophilus stained by the eosin-serum method of Howie and Kirkpatrick. $\times 1800$. 
indole test broth, after incubation for 24 or $48 \mathrm{hr}$ depending on the rapidity of growth, with $0.4 \mathrm{ml}$ of a 0.5 per cent. saline suspension of red cells in a well of a plastic agglutination tray. The tray was left on the bench at room temperature. Positive results were confirmed by retesting with washed, saline suspensions of the organisms harvested from 18-hr chocolate agar slope cultures and adjusted approximately to the opacity of Brown's tube no. 3 (Burroughs Wellcome and Co., London). Similar suspensions of $H$. aegyptius and $H$. influenzae were used as positive and negative controls respectively.

Tests for the presence of $V$ and $X$ factors in saliva. Specimens of freshly collected saliva were thoroughly mixed and then divided into three portions. One portion was centrifuged to deposit the particulate matter, and then the supernatant was taken up in a sterile syringe and passed through a sterile $\mathbf{0 . 2 2} \mu \mathrm{m}$ pore size Millipore filter held in a Swinnex adaptor. The second portion was heated in the waterbath at $60^{\circ} \mathrm{C}$ for $1 \mathrm{hr}$ and then spun and filtered as before. Half of this second filtrate was autoclaved at $121^{\circ} \mathrm{C}$ for $15 \mathrm{~min}$. as was the third portion of whole saliva.

For testing for $\mathrm{V}$ factor four wells were cut in plates of digest agar lightly lawned with an overnight culture of $H$. parainfluenzae. Two wells were filled with the unheated filtered saliva, and to one of these one drop of sterile $0 \cdot 2$ per cent. solution of NAD was added to form a positive control. One of the remaining wells was filled with the filtrate of the heated saliva and the other with the same filtrate after it had been autoclaved.

For testing for X factor, digest agar plates containing $10 \mu \mathrm{g}$ of NAD per ml were lightly lawned with an overnight culture of $H$. influenzae. Four wells were cut and two were filled with the filtrate of unheated saliva with one drop of a sterile 0.2 per cent. solution of haematin $\mathrm{HCl}$ added to one well to form a positive control. One of the remaining wells was filled with the filtrate of the saliva that had been heated at $60^{\circ} \mathrm{C}$ for $1 \mathrm{hr}$ and the other well with autoclaved whole saliva.

The plates were placed in a plastic box moisture chamber and incubated at $37^{\circ} \mathrm{C}$. Plates were inspected daily for growth. Ten saliva specimens were tested.

\section{RESULTS}

\section{Selective medium and haemophilus counts}

Although Evans (1948) reported that the minimal inhibitory concentration of bacitracin for $H$. influenzae type $b$ was 0.6 units per ml, Kohn (1962) found that tablets containing $100 \mu \mathrm{g}$ of bacitracin were useful in isolating haemophili from the respiratory tract; the haemophili formed colonies in the zone of general inhibition around the tablet. More recently, Controni et al. (1968) used disks containing 2 units of bacitracin to isolate haemophili, and Baber (1969) and Crawford, Barden and Kirkman (1969) have described selective media containing 10 units and 5 units of bacitracin per $\mathrm{ml}$ respectively. It was found that the lowest concentration of bacitracin, incorporated in chocolate agar, that effectively suppressed the bulk of the oral flora and least inhibited the haemophili was 10 units per $\mathrm{ml}$. At this concentration $H$. aegyptius strain no. $180 \mathrm{a}$ was completely inhibited and $H$. canis grew poorly. Tests with saliva revealed strains of neisseria whose resistance to bacitracin was equivalent to that of the haemophili and so chocolate agar containing bacitracin alone was insufficiently selective for counting haemophili in saliva.

Fleming and Maclean used penicillin to isolate haemophili from the mouth, but the strains of $H$. parahaemolyticus recovered from oral infections, in contrast with most other species of haemophili, have always been found to be sensitive to penicillin G. Branson (1968) reported that 30 of her 33 strains of H. parahaemolyticus isolated from the throat were inhibited by disks containing 2 units 
of penicillin. However, the oral $H$. parahaemolyticus strains grew well on chocolate agar containing $5 \mu \mathrm{g}$ of cloxacillin per $\mathrm{ml}$, and this medium had a selectivity similar to that of chocolate agar containing $10 \mu \mathrm{g}$ units of bacitracin per $\mathrm{ml}$, i.e., $H$. aegyptius strain 180 a was inhibited, $H$. canis grew poorly and neisseriae resistant to cloxacillin were isolated from saliva specimens. Increasing the concentration of cloxacillin to $10 \mu \mathrm{g}$ per $\mathrm{ml}$ did suppress the growth of

\section{TABLE I}

Summary of the viable counts of haemophili per $m l$ of saliva collected from 50 males and 50 females

\begin{tabular}{c|c|c|c} 
& \multicolumn{2}{|c|}{ No. of specimens with the stated count from } \\
$\begin{array}{c}\text { Count } \\
\left(10^{6}\right)\end{array}$ & males & females & males and females \\
\cline { 2 - 3 } & & & \\
\hline $2 \cdot 5^{*}-5 \cdot 0$ & 1 & 2 & 3 \\
$5 \cdot 1-10 \cdot 0$ & 3 & 6 & 9 \\
$10 \cdot 1-15 \cdot 0$ & 6 & 4 & 10 \\
$15 \cdot 1-20 \cdot 0$ & 3 & 6 & 9 \\
$20 \cdot 1-25 \cdot 0$ & 3 & 4 & 7 \\
$25 \cdot 1-30 \cdot 0$ & 8 & 5 & 13 \\
$30 \cdot 1-35 \cdot 0$ & 5 & 7 & 72 \\
$35 \cdot 1-40 \cdot 0$ & 3 & 4 & 10 \\
$40 \cdot 1-45 \cdot 0$ & 7 & 3 & 4 \\
$45 \cdot 1-50 \cdot 0$ & 3 & 1 & 3 \\
$50 \cdot 1-55 \cdot 0$ & 2 & 1 & 13 \\
$55 \cdot 1-94 \cdot 2 *$ & 6 & 7 & \\
\hline
\end{tabular}

Mean count (and standard error of mean) (106) for

\begin{tabular}{c|c|c} 
males & females & males and females \\
\hline $33.42(2 \cdot 79)$ & $30 \cdot 16(2 \cdot 84)$ & $31 \cdot 79(1 \cdot 98)$ \\
\hline
\end{tabular}

* Lowest and highest counts recorded.

most of the neisseriae, but the oral strains of $H$. parahaemolyticus either grew poorly or were completely inhibited by this concentration. Fortunately, it was found that the neisseriae recovered from the bacitracin chocolate agar plates failed to grow on cloxacillin chocolate agar and vice versa. Chocolate agar containing 10 units of bacitracin per $\mathrm{ml}$ and $5 \mu \mathrm{g}$ of cloxacillin per $\mathrm{ml}$ proved to be a most satisfactory medium for counting haemophili in saliva specimens, although $H$. aegyptius strain no. 180a and $H$. canis would not grow on it.

H. aegyptius strain no. 180a is the type species and was found to be moderately resistant to bacitracin and sensitive to cloxacillin. It was thought that cloxacillin sensitivity might provide a simple test for differentiating $H$. aegyptius from $H$. influenzae, but strains no. $180 \mathrm{a}$ and $128 \mathrm{a}$ of $H$. aegyptius are resistant to cloxacillin and grow well on the selective medium. 
All the test strains of haemophili grew well on chocolate agar containing $50 \mu \mathrm{g}$ of vancomycin per $\mathrm{ml}$, but this antibiotic was least effective in suppressing the oral neisseriae, and these organisms were not eliminated by combining vancomycin with bacitracin or cloxacillin.

At the dilutions of saliva plated, the bacitracin-cloxacillin chocolate agar was found to be completely selective for haemophili. Parallel counts of

TABLE II

Numbers of haemophili per sq. cm of oral mucosa recovered from ten subjects by means of an area-sampling technique

\begin{tabular}{|c|c|c|c|}
\hline \multirow{2}{*}{ Subject } & \multicolumn{3}{|c|}{ Number of haemophili per $\mathrm{cm}^{2}$ from } \\
\hline & cheek & palate & tongue \\
\hline $\begin{array}{ll}\text { Male } & \text { no. } 1 \\
& \text { no. } 2 \\
\text { no. } 3 \\
\text { no. } 4 \\
\text { no. } 5\end{array}$ & $\begin{array}{l}2250 \\
5800 \\
4300 \\
2150 \\
2450\end{array}$ & $\begin{array}{r}200 \\
2500 \\
13,150 \\
1650 \\
3400\end{array}$ & $\begin{array}{r}1950 \\
7150 \\
9950 \\
6500 \\
17,300\end{array}$ \\
\hline Mean for males & 3390 & 4180 & 8750 \\
\hline $\begin{aligned} & \text { Female } \text { no. } 1 \\
& \text { no. } 2 \\
& \text { no. } 3 \\
& \text { no. } 4 \\
& \text { no. } 5\end{aligned}$ & $\begin{array}{r}5300 \\
850 \\
5250 \\
700 \\
9650\end{array}$ & $\begin{array}{r}3800 \\
11,200 \\
9100 \\
7400 \\
4350\end{array}$ & $\begin{array}{l}8950 \\
3600 \\
5800 \\
7200 \\
5750\end{array}$ \\
\hline Mean for females & 4350 & 7170 & 6260 \\
\hline Over-all mean (and standard error) & $3870(869)$ & $5675(1365)$ & $7415(1322)$ \\
\hline
\end{tabular}

suspensions of haemophili plated on the selective medium and on plain chocolate agar showed no statistically significant difference. The plate counts were incubated in air +5 per cent. $\mathrm{CO}_{2}$ because in a trial series it was found that counts were frequently two-fold, and occasionally as much as ten-fold, higher than when incubated in air alone. Zinnemann et al. (1968) have suggested that $\mathrm{CO}_{2}$-dependent haemophili are part of the normal oral flora and it may well be that many of the colonies counted in this work consisted of such haemophili.

The results of the counts of haemophili in saliva specimens collected from 50 males and 50 females are summarised in table I. The means of the two groups do not differ significantly when tested at the 5 per cent. level. The 95 per cent. confidence limits for the combined mean are $27.8 \times 10^{6}$ and $35.7 \times 10^{6}$ haemophili per $\mathrm{ml}$ of saliva.

Table II shows the number of haemophili recovered from the cheek, palate and tongue of ten subjects by the area-sampling method. Neisseriae resistant to the bacitracin-cloxacillin combination were encountered in this survey. 
Although these neisseriae occurred in small numbers and most of them produced colonies that were easily distinguishable from haemophili by form and pigmentation, a large number of doubtful colonies had to be examined by staining. This made the counts tedious to perform and the size of the project was therefore limited.

\section{Types of haemophili in saliva specimens}

The numbers of five saliva specimens each from males and females were randomly chosen before the project began, and when the counts had been

TABLE III

Growth-factor requirements of the individual colonies of haemophili from saliva specimens from five male and five female subjects

\begin{tabular}{|c|c|c|c|c|c|c|c|}
\hline \multirow{3}{*}{$\begin{array}{l}\text { Specimen } \\
\text { no. }\end{array}$} & \multicolumn{7}{|c|}{ Number of colonies that } \\
\hline & \multirow{2}{*}{$\begin{array}{c}\text { were } \\
\text { counted }\end{array}$} & \multirow{2}{*}{$\begin{array}{l}\text { grew on sub- } \\
\text { culture to } \\
\text { chocolate } \\
\text { agar }\end{array}$} & \multicolumn{3}{|c|}{ required for growth } & \multirow{2}{*}{$\begin{array}{l}\text { grew on } \\
\text { plain digest } \\
\text { agar* }\end{array}$} & \multirow{2}{*}{$\begin{array}{l}\text { failed to grow on } \\
\text { subculture to } \\
\text { growth-factor } \\
\text { test media }\end{array}$} \\
\hline & & & $\begin{array}{l}V \text { and } X \\
\text { factors }\end{array}$ & $V$ factor & $\mathrm{X}$ factor & & \\
\hline $\begin{array}{l}\text { M4 } \\
\text { M13 } \\
\text { M23 } \\
\text { M26 } \\
\text { M40 } \\
\text { F6 } \\
\text { F21 } \\
\text { F33 } \\
\text { F41 } \\
\text { F49 }\end{array}$ & $\begin{array}{l}437 \\
384 \\
146 \\
260 \\
369 \\
206 \\
386 \\
113 \\
316 \\
320\end{array}$ & $\begin{array}{r}390 \\
366 \\
118 \\
253 \\
334 \\
182 \\
335 \\
95 \\
279 \\
299\end{array}$ & $\begin{array}{r}13 \\
28 \\
15 \\
6 \\
44 \\
25 \\
31 \\
0 \\
4 \\
17\end{array}$ & $\begin{array}{r}351 \\
328 \\
103 \\
245 \\
276 \\
150 \\
285 \\
95 \\
272 \\
267\end{array}$ & $\begin{array}{l}0 \\
0 \\
0 \\
0 \\
0 \\
0 \\
0 \\
0 \\
0 \\
0\end{array}$ & $\begin{array}{r}(5) \\
(38) \\
(13) \\
(26) \\
(3) \\
(18) \\
(0) \\
(11) \\
(47) \\
(8)\end{array}$ & $\begin{array}{r}26 \\
10 \\
0 \\
2 \\
14 \\
7 \\
19 \\
0 \\
3 \\
15\end{array}$ \\
\hline All specimens & 2937 & 2651 & 183 & 2372 & 0 & (169) & 96 \\
\hline
\end{tabular}

* Neisseriae contaminating colonies consisting mainly of haemophili. $\mathrm{M}=$ Male $; \mathrm{F}=$ female.

performed all the colonies on the plates from these specimens were subcultured and then examined for $\mathrm{V}$ and $\mathrm{X}$ growth-factor requirements. The results are shown in table III. There was a $9 \cdot 7$ per cent. loss on subculture of these colonies to a second plate of selective chocolate agar, and a further $3 \cdot 6$ per cent. of these isolates failed to grow on the growth-factor plates. All 169 of the isolates that grew on plain digest agar proved to be neisseriae present as contaminants in haemophilus colonies. The growth from the corresponding colonies on the $\mathrm{V}+\mathrm{X}$ factor plate was streaked on selective chocolate agar to obtain a pure culture of the haemophilus which was then retested; the results have been included in table III. Paradoxically, none of these neisseriae was capable of growth on the selective chocolate agar in pure culture. Of the 2555 isolates that grew on the growth-factor plates 92.8 per cent. were V-dependent and the remaining $7 \cdot 2$ per cent. required $\mathrm{V}$ and $\mathrm{X}$ factors. 
None of the $\mathrm{V}+\mathrm{X}$ dependent isolates produced iridescent colonies or haemagglutinated human group-O red cells. They all reduced nitrate and were bile soluble; 76 isolates ( 41.5 per cent.) produced indole, and 52 isolates (28.4 per cent.) were haemolytic. They were catalase-positive, although there was great variation in the vigour of the reaction, and feebly oxidase-positive.

TABLE IV

Subdivision of 2372 oral isolates of V-dependent haemophili

\begin{tabular}{|c|c|c|c|c|c|}
\hline \multirow{2}{*}{ Character } & \multicolumn{5}{|c|}{ Presence of the stated characters in members of group } \\
\hline & 1 & 2 & 3 & 4 & 5 \\
\hline $\begin{array}{l}\text { Growth in } 0 \cdot 2 \text { per cent. Teepol broth } \\
\text { Capsulation } \\
\text { Haemolysis } \\
\text { Haemagglutination of human } \\
\text { group-O red cells }\end{array}$ & $\frac{+}{-}$ & $\begin{array}{l}+ \\
+ \\
-\end{array}$ & $\frac{-}{ \pm}$ & $\begin{array}{l}- \\
\overline{+} \\
+\end{array}$ & $\begin{array}{l}\overline{-} \\
-\end{array}$ \\
\hline
\end{tabular}

\begin{tabular}{|c|c|c|c|c|c|}
\hline \multirow{2}{*}{ Specimen number } & \multicolumn{5}{|c|}{$\begin{array}{l}\text { Number of colonies from the stated specimen, and from the } \\
\text { total, that belonged to group }\end{array}$} \\
\hline & 1 & 2 & 3 & 4 & 5 \\
\hline $\begin{array}{l}\text { M4 } \\
\text { M13 } \\
\text { M23 } \\
\text { M26 } \\
\text { M40 } \\
\text { F6 } \\
\text { F21 } \\
\text { F33 } \\
\text { F41 } \\
\text { F49 }\end{array}$ & $\begin{array}{r}194 \\
219 \\
71 \\
105 \\
173 \\
94 \\
128 \\
82 \\
197 \\
146\end{array}$ & $\begin{array}{r}21 \\
18 \\
4 \\
0 \\
22 \\
3 \\
45 \\
0 \\
15 \\
19\end{array}$ & $\begin{array}{r}0 \\
9 \\
14 \\
8 \\
18 \\
0 \\
26 \\
6 \\
13 \\
0\end{array}$ & $\begin{array}{r}28 \\
23 \\
3 \\
42 \\
10 \\
12 \\
54 \\
5 \\
17 \\
35\end{array}$ & $\begin{array}{r}108 \\
59 \\
11 \\
90 \\
53 \\
41 \\
32 \\
2 \\
30 \\
67\end{array}$ \\
\hline All specimens & $\begin{array}{c}1409 \\
(59 \cdot 40 \\
\left.\text { per cent. }{ }^{*}\right)\end{array}$ & $\begin{array}{c}147 \\
(6 \cdot 20 \\
\text { per cent. })\end{array}$ & $\begin{array}{c}94 \\
(3 \cdot 96 \\
\text { per cent. })\end{array}$ & $\begin{array}{c}229 \\
(9 \cdot 65 \\
\text { per cent.) }\end{array}$ & $\begin{array}{c}493 \\
(20 \cdot 78 \\
\text { per cent.) }\end{array}$ \\
\hline
\end{tabular}

* Percentage of the total belonging to the stated group.

$+=$ Character present; $-=$ character absent.

The 2372 isolates of V-dependent haemophili reduced nitrate, failed to produce indole and grew on MacConkey agar, but were bile soluble. Although many of the catalase and oxidase reactions were very feeble none could be reliably classed as negative. The results of the remaining tests, which serve to divide the isolates into five groups, are listed in table IV.

The organisms in group 1 (Teepol-resistant, non-capsulated and not haemolytic or haemagglutinating) are almost certainly the distinct type of oral $H$. parainfluenzae described by Fleming and Maclean. When grown on chocolate agar in air +5 per cent. $\mathrm{CO}_{2}$, well isolated colonies may reach a diameter of up 
to $0.9 \mathrm{~cm}$. The colonies, which are flat, slightly wrinkled and granular, can be slid intact across the surface of the agar as described by Fleming and Maclean. These authors found their organisms to be indole-negative, and to ferment glucose and sucrose but not dulcitol, lactose or mannitol. Twenty group-1 isolates from each saliva specimen were tested and found to give the same results with these carbohydrates. These organisms give clearly positive catalase and oxidase reactions and reduce nitrite.

The group-2 organisms appear to be capsulated variants of group 1. They differ only in forming smaller colonies, not more than $0.6 \mathrm{~cm}$ in diameter, which are smooth, suspend uniformly in saline and cannot be moved intact across the agar surface. On translucent media, illuminated and examined as described by Pittman, the colonies iridesce brightly. The capsules, though not large, can be demonstrated by staining methods (figure). None of the group-2 organisms was agglutinated by $H$. influenzae typing sera types $a-f$.

The group-4 organisms form another fairly well-demarcated group; they are characterised by haemagglutination and the production of clear zones of beta-haemolysis, and also grow much better on blood agar than do the other groups of V-dependent haemophili. After 24 hours' incubation in air on horse blood agar they form colonies $c .2 \mathrm{~mm}$ in diameter, whereas only a few isolates in the other groups produce colonies as large as $1 \mathrm{~mm}$ in diameter under these conditions. Branson noted that $H$. parahaemolyticus would not grow on human or sheep blood agar and this was confirmed with the group-4 strains, but, of course, organisms in the other groups also fail to grow because these media are lacking in $\mathrm{V}$ factor. On human and sheep blood agar containing added NAD the group-4 organisms grow and produce zones of beta-haemolysis. Only 31 isolates (13.5 per cent.) in this group reduced nitrite.

\section{$V$ and $X$ factors in saliva}

The growth that resulted when a loopful of saliva was spread over a segment of a plate of digest agar was found to support satellite growth of strains of $H$. parainfluenzae streaked near by. A similar test, but with NAD added to the medium and with strains of $H$. influenzae as test organisms, failed to demonstrate satellitism. Filtrates of saliva placed in wells in digest agar plates failed to facilitate growth of $H$. parainfluenzae. Filtrates of saliva that had been heated at $60^{\circ} \mathrm{C}$ for $1 \mathrm{hr}$ did support growth and this property was abolished by autoclaving. Growth of $H$. influenzae did not occur on digest agar containing NAD around wells filled with autoclaved saliva or with filtrates of fresh or heated saliva.

\section{DISCUSSION}

Haemophili form a substantial part of the normal oral flora and can be isolated from any part of the mouth by means of a selective medium. With the exception of some specimens from the root canals of infected teeth, they can be recovered from all oral infections.

From the mean saliva count of $31.79 \times 10^{6}$ haemophili per $\mathrm{ml}$, a film of saliva $1 \mathrm{~cm}$ square and $1 \mu \mathrm{m}$ thick would be expected to contain $c .3179$ organisms. 
When allowance is made for the relative surface areas of cheek, palate and tongue, and the sampling and technical errors in the counts, this figure is in satisfactory agreement with the mean surface area haemophilus counts of 3870 , 5675 and 7415 per $\mathrm{cm}^{2}$.

The large number of isolates examined were all from only ten subjects. Consequently, the results of the various tests were highly uniform and are in no way comparable with results obtained by studying a similar number of strains each from a separate source. A quantitative study of a few specimens was preferred to a qualitative search of a large number of specimens because the microbes involved in most dental infections are part of the normal oral flora and only large quantitative changes in the flora of a particular site are of significance in trying to assess pathogenicity.

A number of investigators have isolated haemophili that require only $\mathrm{X}$ factor from oral sources. The failure to find them in this study may mean that they are present only in very small numbers or that they are sensitive to the bacitracin-cloxacillin combination used in the selective medium. H. aphrophilus grows well on the selective medium whereas $H$. canis is inhibited. Attempts to recover X-factor requiring haemophili from undiluted saliva on selective autoclaved blood agar have so far been unsuccessful.

The finding of $H$. parahaemolyticus in so many dental clinical specimens led to the present investigation, and it was therefore surprising to find that these organisms constitute only $c$. 13.6 per cent. of the V-dependent haemophili present in the mouth. Haemolytic strains grow very much better on blood agar plates than do other haemophili; this, and the presence of the zones of beta-haemolysis, almost certainly led to their being further examined, whereas the non-haemolytic colonies were frequently overlooked in our routine work. Seventy per cent. of the isolates of $H$. parahaemolyticus from saliva agglutinated human red cells but, although the haemagglutinin of $H$. aegyptius has been studied in some detail (Mann and Rheins, 1968), there is at present no reason for regarding this property as concerned with pathogenicity.

The only description of capsulated $H$. parainfluenzae in the literature appears to be the reference to unpublished work by Alexander (1965) who states that iridescence and capsule swelling can be demonstrated and that there is more than one serological type. Turk and May (1967) state that these strains are very uncommon, but the results of this work suggest that they are present in most mouths at an average concentration of $c .1 \cdot 8 \times 10^{6}$ per ml of saliva. The explanation seems to be simply that there have been no previous studies of the oral haemophili on media that support good growth yet are highly selective. The pathogenicity of these strains is being investigated. A culture of a group-2 strain has been placed in the National Collection of Type Cultures, H. parainfluenzae (no. NCTC10665).

Turk and May believe the distinction between non-capsulated $H$. influenzae and $H$. parainfluenzae to be of little clinical significance. Since the pathogenicity of non-capsulated $H$. influenzae in chronic bronchitis is well documented, the large numbers of haemophili in the mouth would seem to possess considerable pathogenic potential. Disease of the supporting tissues of the teeth is the most 
widespread chronic disease affecting mankind. It has certain similarities with chronic bronchitis in that initial micro-anatomical changes facilitate an increase in the mass of the normally associated bacteria. The larger numbers of bacteria then provoke inflammatory changes, which again tend to promote further bacterial accumulation, and so on. The possible association between haemophili and peridontal disease is now being investigated.

Despite the large numbers of haemophili present, $\mathrm{V}$ factor could be detected in saliva only when it was heated at $60^{\circ} \mathrm{C}$ for $1 \mathrm{hr}$. Since it seems unlikely that intact, living bacteria or cells would release a metabolite such as NAD, this finding suggests that haemophili are dependent on the death of associated bacteria for their supply of $\mathrm{V}$ factor. It would be interesting to know whether haemophili can colonise the mouth and upper respiratory tract of germ-free animals. No X factor, or source of $\mathrm{X}$ factor, could be detected in saliva; moreover, the growing mass of bacteria in saliva failed to support satellite growth of $H$. influenzae on V-factor plates. Although this conveniently explains the predominance of V-dependent haemophili in saliva, it is a surprising finding. Pickett and Stewart (1953) have shown that catalase-positive organisms can meet the X-factor requirements of $H$. influenzae, and, in this work, it was found that the relatively strongly catalase-positive $\mathrm{V}$-dependent haemophili of groups 1 and 2 would support satellite growth of $H$. influenzae on V-factor plates.

\section{SUMMARY}

The number of haemophili in saliva was estimated by growth on a selective medium consisting of chocolate agar containing bacitracin (10 units per $\mathrm{ml}$ ) and cloxacillin $(5 \mu \mathrm{g}$ per $\mathrm{ml}$ ). The mean count of 100 saliva specimens was $31.79 \times 10^{6}$ haemophili per ml of saliva.

Area sampling on to selective medium from the cheek, palate and tongue of ten subjects gave mean counts of haemophili of 3870,5675 and 7415 per $\mathrm{cm}^{2}$ respectively.

Examination of the colonies on ten randomly selected saliva plate counts showed that 92.8 per cent. were V-dependent and that the remaining 7.2 per cent. required $\mathrm{V}$ and $\mathrm{X}$ factors. No haemophili requiring only $\mathrm{X}$ factor were isolated. The V-dependent haemophili could be subdivided into five groups on the basis of growth in broth containing $0 \cdot 2$ per cent. Teepol, production of capsules, agglutination of human red blood cells, and beta-haemolysis on horse blood agar.

The mixed mass of oral bacteria when growing in culture will support satellite growth of $H$. parainfluenzae, but $\mathrm{V}$ factor could be demonstrated in saliva only when it had been heated at $60^{\circ} \mathrm{C}$ for $1 \mathrm{hr}$. Neither the saliva nor the bacteria in it was a source of $\mathrm{X}$ factor.

\section{REFERENCES}

AleXANDer, HATtiE E. - . . . . 1965. In Bacterial and mycotic infections of man, 4th ed., edited by R. J. Dubos and J. G. Hirsch, London, p. 730.

BABer, K. G. • . . . . . . . 1969. J. Med. Lab. Technol., 26, 391. 
Bisset, K. A., And Davis, G. H. G. . 1960. The microbial flora of the mouth, London.

Branson, Dorothy . . . . . . . 1968. Appl. Microbiol., 16, 256.

Burnett, G. W., ANd Scherp, H. W. . 1968. Oral microbiology and infectious disease, 3rd ed., Baltimore, p. 279.

Controni, G., Waheed Kahn, M., 1968. Regist. Med. Technol. Tech. Bull., 38, 94. Patrick, J. R., AND Ross, $\mathbf{S}$.

Cowan, S. T., AND Steel, K. J. . . 1965. Manual for the identification of medical

Crawford J. J. bacteria, Cambridge.

KIRKMAN, J. B., JR



EVANS, Florence L. · . . . . . . 1948. J. Bact., 56, 507.

Fleming, A., ANd Maclean, I. H. . . 1930. Br. J. Exp. Path, 11, 127.

Holt, L. B. . . . . . . . . . 1962. J. Gen. Microbiol., $27,317$.

Howie, J. W., AND KirkPatrick, J. . . 1934. J. Path. Bact., 39, 165.

Jameson, J. E., AND EMBerley, N. W. . 1956. J. Gen. Microbiol., 15, 198.

Johanson, W. G., Pierce, A. K., And 1969. Appl. Microbiol., 18, 276.

SANFORD, J. P.

KoHN, J. . . . . . . . . . 1962. Dapim Reff. uim, 21, 365.

MANN, J. M., AND RheIns, M. A. . 1968. Appl. Microbiol., 16, 1343.

Nolte, W. A. . . . . . . . . . . 1968. In Oral microbiology, St Louis, pp. 3-37.

Pickett, M. J., and Stewart, R. M. 1953. Amer. J. Clin. Path., 23, 713.

Pittman, Margaret . . . . . . 1931. J. Exp. Med., 53, 471.

Pritchett, Ida W., ANd Stillman, E. G. 1919. Ibid., 29, 259.

StOKes, E. JoAN . . . . . . . 1968. Clinical bacteriology, 3rd ed., London.

TuRK, D. C., AND MAY, J. R. 1967. Haemophilus influenzae: its clinical importance, London, p. 11.

Zinnemann, K., Rogers, K. B., Frazer, 1968. J. Path. Bact., 96, 413. JOYCE, AND BOYCE, J. M. H. 